\title{
In vivo measurement of strontium absorption from the rumen of dairy cows as an index of calcium absorption capacity
}

\author{
Michelle L. Hyde, ${ }^{1}$ Mirja R. Wilkens, ${ }^{2}$ and David R. Fraser ${ }^{1 *}$ \\ ${ }^{1}$ Sydney School of Veterinary Science, University of Sydney, NSW 2006, Australia \\ ${ }^{2}$ Institute of Physiology and Cell Biology, University of Veterinary Medicine Hannover Foundation, D-30173 Hanover, Germany
}

\section{ABSTRACT}

Absorption of dietary calcium from the rumen is a quantitatively important process in calcium homeostasis of ruminants. In 3 separate experiments in dairy cows, we applied a technique developed in sheep to measure the rate of strontium $(\mathrm{Sr})$ absorption from the rumen as an indicator of calcium absorption capacity. Absorption from the rumen after an oral dose of $\mathrm{SrCl}_{2}$ resulted in a maximum plasma concentration of Sr after $1 \mathrm{~h}$, whereas absorption from the small intestine after injection of $\mathrm{SrCl}_{2}$ into the abomasum through a cannula occurred more slowly. The second experiment demonstrated that the calcium absorption capacity index of the rumen was significantly greater in 21 lactating Friesian cows $(230 \pm 66$, mean $\pm \mathrm{SEM})$ than in 6 mature, nonlactating, nonpregnant heifers $(101 \pm 21$, mean \pm SEM). In a third experiment, we compared clinically normal cows at the onset of lactation with those that developed parturient paresis. In cows that developed severe hypocalcemia, plasma concentrations of $1,25(\mathrm{OH})_{2} \mathrm{D}$ were significantly elevated $(144 \pm 60 \mathrm{pg} / \mathrm{mL}$ vs. $90 \pm$ $54 \mathrm{pg} / \mathrm{mL}$; means \pm SEM) and their rumen calcium absorption index was significantly decreased compared with that of clinically normal cows. Evidence suggested that mobilization of calcium from bone as lactation commenced was significantly depressed in paretic cows compared with those that did not show clinical signs of hypocalcemia. Moreover, ruminal stasis suppressed the absorption of calcium from the rumen. We conclude that measurement of $\mathrm{Sr}$ concentration in blood plasma after an oral dose of $\mathrm{SrCl}_{2}$ into the rumen can be used as an index of rumen calcium absorption capacity under different states of calcium homeostasis.

Key words: rumen, calcium absorption, lactation, parturient paresis

Received November 26, 2018.

Accepted March 3, 2019.

*Corresponding author: david.fraser@sydney.edu.au

\section{INTRODUCTION}

The maintenance of normal blood calcium concentration is a particular challenge for high-producing dairy cows at the onset of lactation (Blum et al., 1972). Two mechanisms that compensate for the loss of calcium in milk are increased absorption of calcium from the alimentary tract and release of calcium from the dissolution of bone mineral. Although more than $75 \%$ of dairy cows may become hypocalcemic at the start of lactation (Rodríguez et al., 2017), most show no clinical abnormality at that time. Some cows, however, develop parturient paresis and would die from hypocalcemia without treatment.

Various strategies, such as feeding diets prepartum with low cation-to-anion ratios (Ender et al., 1971), inducing an early calcium homeostasis response by feeding calcium-deficient diets (Goings et al., 1974), prepartum treatment with vitamin D metabolites (Hodnett et al., 1992), or oral administration of calcium at calving (Oetzel, 2013), minimize the proportion of cows that develop clinical hypocalcemia at parturition. Despite the partial success of these empirical prevention strategies, the mechanism of the physiological defect that results in uncompensated hypocalcemia remains undefined. The fact that some cows with parturient paresis can have high blood plasma concentrations of parathyroid hormone (PTH) and 1,25-dihydroxyvitamin D $\left[1,25(\mathrm{OH})_{2} \mathrm{D}\right.$; Ramberg et al., 1984$]$ suggests that the endocrine control of calcium homeostasis is responding appropriately to the rapid decline in plasma calcium concentration. In that instance, there is apparent endorgan resistance to the endocrine stimulus. However, in other cows with clinical hypocalcemia, renal production of $1,25(\mathrm{OH})_{2} \mathrm{D}$ in response to high circulating levels of PTH may be muted, suggesting that the endocrine role of the kidney in producing $1,25(\mathrm{OH})_{2} \mathrm{D}$ may be refractory to the needs of calcium homeostasis (Goff et al., 2014).

Calcium absorption from the alimentary tract of ruminants occurs not only in the small intestine but also in the rumen (Höller et al., 1988; Beardsworth et al., 
1989; Wadhwa and Care, 2000). A technique developed in humans to estimate calcium intestinal absorption capacity (Sips et al., 1994) has been adapted to determine the calcium absorption capacity from the rumen and small intestine of sheep (Hyde and Fraser, 2014). This method measures the concentration of strontium ions in blood after administration of a solution of strontium chloride to either the rumen or the small intestine. In sheep, the calcium absorption capacity from the rumen, as demonstrated by the absorption pattern of strontium, suggested that a major site for calcium absorption was through the rumen mucosa. This strontium dosing technique has now been applied to dairy cows and the calcium absorption capacity of the rumen has been characterized in cows at the onset of lactation.

\section{MATERIALS AND METHODS}

All experimental procedures with dairy cows were approved by the Animal Ethics Committee of the University of Sydney. We determined the calcium absorption capacity of the rumen by measuring the strontium (Sr) concentration in blood plasma after oral administration of an aqueous solution of $\mathrm{SrCl}_{2}$ into the rumen of cows in different states of calcium homeostasis. All cows in this study were from a commercial dairy herd maintained in paddocks outdoors, where the diet was grazed pasture with dominant kikuyu/paspalum and rye/white clover mix, depending on the season. Small amounts of grain were fed at milking.

Three separate investigations were undertaken: (1) a comparison of $\mathrm{Sr}$ absorption from the rumen and absorption when $\mathrm{Sr}$ was injected directly into the abomasum; (2) a comparison of rumen Sr absorption in lactating and nonlactating cows; and (3) a comparison between clinically normal cows and those with parturient paresis at the onset of lactation.

\section{Rumen Calcium Absorption Capacity}

We determined calcium absorption capacity from the rumen in a group of 8 multiparous lactating Friesian cows of various ages on a pasture-based diet on a commercial farm. Each was dosed orally with $2 \mathrm{~g}$ of $\mathrm{Sr}$ as $\mathrm{SrCl}_{2}$ in $50 \mathrm{~mL}$ of solution. Blood samples were taken by tail vein puncture at intervals from 0 to $6 \mathrm{~h}$ after dosing. Plasma was prepared and stored at $-20^{\circ} \mathrm{C}$. The strontium content was measured by graphite furnace atomic absorption spectrometry. Plasma samples were thawed at room temperature and mixed thoroughly. Each sample was diluted with an appropriate amount $(3-8 \mathrm{~mL})$ of nitric acid $(0.01 \% \mathrm{vol} / \mathrm{vol})$-Triton X-100 $(0.002 \% \mathrm{vol} / \mathrm{vol})$ solution. Standards were prepared from a $1.00 \mathrm{mg} / \mathrm{mL}$ strontium nitrate standard solution
(BDH Chemicals/VWR International, Radnor, PA). The Sr concentration in each sample was measured in triplicate. Assay calibration was monitored using inhouse control human serum samples containing low, medium, and high concentrations of strontium. All glassware was soaked in 10\% nitric acid and rinsed with Milli Q-grade double deionized water.

The calcium absorption capacity was expressed as an index; that is, the plasma concentration of strontium at $1.5 \mathrm{~h}$ after dosing minus the initial plasma strontium concentration, adjusted for a BW of $500 \mathrm{~kg}$ :

$$
\text { Calcium absorption index }=\frac{\left[\mathrm{Sr}_{90}\right]-\left[\mathrm{Sr}_{0}\right]}{\mathrm{BW}} \times 500 \text {, }
$$

where $\left[\mathrm{Sr}_{90}\right]=\mathrm{Sr}$ concentration in plasma $(\mathrm{ng} / \mathrm{mL}) 90$ min after an oral dose of $2 \mathrm{~g}$ of $\mathrm{Sr}$ as $\mathrm{SrCl}_{2}$ in $50 \mathrm{~mL}$ of water and $\left[\mathrm{Sr}_{0}\right]=\mathrm{Sr}$ concentration in plasma $(\mathrm{ng} / \mathrm{mL})$ at the time of dosing.

To confirm the pattern of absorption from the rumen, we injected 3 lactating Friesian cows with $10 \mathrm{~g}$ of Sr, as $\mathrm{SrCl}_{2}$ in $50 \mathrm{~mL}$, directly into the rumen through the abdominal wall. The site of injection was surgically prepared and the skin and underlying abdominal muscles were anesthetized by injection of $6 \mathrm{~mL}$ of lignocaine. Blood samples for strontium analysis were collected from indwelling jugular cannulas at intervals from 0 to $5 \mathrm{~h}$ after dosing.

\section{Post-Rumen Calcium Absorption Capacity}

Four mature lactating Friesian cows, each with a surgically implanted indwelling abomasal cannula, were housed indoors in stanchions and fed a diet of chaff and grain. The cannula of each cow was injected with $2 \mathrm{~g}$ of $\mathrm{Sr}$, as $\mathrm{SrCl}_{2}$ in $50 \mathrm{~mL}$. Blood samples for $\mathrm{Sr}$ analysis were collected from indwelling jugular cannulas at intervals from 0 to $6 \mathrm{~h}$ after dosing.

\section{Rumen Calcium Absorption Capacity at Onset of Lactation}

We studied the calcium absorption capacity and other variables in 14 multiparous Friesian cows of various ages in a commercial herd around the time of calving. Measurements were made approximately 3 wk before calving, within $24 \mathrm{~h}$ of calving, and approximately $3 \mathrm{wk}$ after calving. Blood samples were collected before each rumen calcium absorption capacity test, and plasma samples were analyzed for $1,25(\mathrm{OH})_{2} \mathrm{D}$, total calcium, and hydroxyproline concentrations.

Plasma $1,25(\mathrm{OH})_{2} \mathrm{D}$ was determined by a competitive protein binding assay using the method of Reinhardt 
and Hollis (1986), with modifications as described by Seshadri et al. (1985). Calf thymus vitamin D receptor was prepared by the method of Reinhardt and Hollis (1986). Plasma total calcium concentration was determined by flame atomic absorption spectroscopy. Plasma hydroxyproline concentration was determined by the colorimetric method of Dabev and Struck (1971).

\section{Statistical Analysis}

The statistical significance of differences of mean data values from 2 experimental groups was assessed by Student's $t$-test as described by Steele and Torrie (1981). Where there were more than 2 experimental groups, the significant difference of mean data values was determined by ANOVA (Steele and Torrie, 1981). Any significant differences found between experimental groups were further evaluated by a multiple comparison test (least significant difference test). All statistical analyses were performed using Minitab (version 7.1; Minitab Inc., State College, PA) or SAS (SAS Institute Inc., Cary, NC) statistical programs.

\section{RESULTS AND DISCUSSION}

\section{Comparison of Calcium Absorption from the Rumen and Small Intestine}

We compared the pattern of absorption of Sr from the rumen and the small intestine, after administering solutions of $\mathrm{SrCl}_{2}$. The appearance over time of $\mathrm{Sr}$ in blood plasma is shown in Figure 1, after a dose of 2 $\mathrm{g}$ of $\mathrm{Sr}$ was administered to lactating Friesian cows, either orally or into the abomasum through surgically implanted cannulas. It is notable that the background plasma $\mathrm{Sr}$ concentration in cows not previously dosed with $\mathrm{Sr}$ was in the range of 210 to $230 \mathrm{ng} / \mathrm{mL}$. The rate of strontium absorption from the rumen reached a maximum within $1 \mathrm{~h}$ after the oral dose. Plasma Sr levels showed a wide variation between cows, but the apparent rate of absorption from the rumen was relatively constant between 1 and $4 \mathrm{~h}$ after dosing. Although the plasma Sr concentration after injection into the abomasum was only about one-third of that observed when absorbed from the rumen, it remained constant for 3 $\mathrm{h}$ and then began to increase, consistent with the bulk of the dose having passed into the duodenum by that time.

Unlike in our studies with sheep (Hyde and Fraser, 2014), we were unable to cause closure of the esophageal groove by treatment of cows with vasopressin. Hence, oral administration in cows always directed the tracer dose of $\mathrm{Sr}$ as a bolus into the rumen contents. Nevertheless, an oral dose of Sr might bypass the rumen if the esophageal groove were to close. Therefore, to verify that $\mathrm{Sr}$ was being absorbed directly from the rumen, we measured plasma $\mathrm{Sr}$ with time after direct injection of $10 \mathrm{~g}$ of $\mathrm{Sr}$ as $\mathrm{SrCl}_{2}$ in $50 \mathrm{~mL}$ through the abdominal wall into the lumen of the rumen. The plasma concentration increased immediately after injection and remained constant for the following $5 \mathrm{~h}$ (Figure 2), indicating a constant rate of absorption across the rumen mucosa.

However, all 3 cows experienced some degree of bloating approximately $45 \mathrm{~min}$ after rumen injection, which subsided about $3 \mathrm{~h}$ later. All cows defecated, urinated, and drank water during the sampling period and did not appear distressed. Nevertheless, a large decrease in milk yield was observed in all 3 cows over the next $7 \mathrm{~d}$. All cows had a normal appetite, no weight loss, and no sign of infection. Milk yield did not return to predosing values until 2 wk later. We assume that the rumen injection procedure caused temporary but significant rumen stasis. One possible cause of rumen stasis might have been penetration of the lignocaine anesthetic into the abdominal cavity with a consequent inhibition of rumen muscle contractions. Alternatively, stimulation of serosal receptors in the rumen wall by the penetrating needle might have inhibited centrally controlled motility of the forestomachs. Although we observed a constant rate of absorption, this was considerably less than when $\mathrm{Sr}$ was directed into the rumen of these cows by oral dosing (Figure 2). Because changes in plasma $\mathrm{Sr}$ concentration could be readily detected with oral doses of $2 \mathrm{~g}$ of $\mathrm{Sr}$, this quantity was used to determine rumen Sr absorption in subsequent studies.

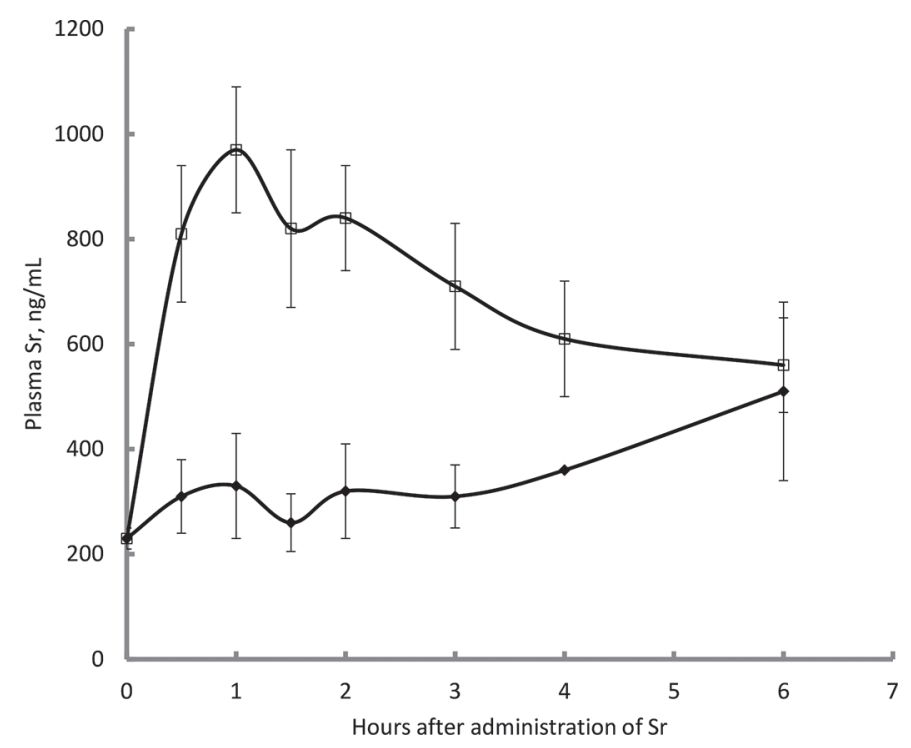

Figure 1. Strontium concentration (mean $\pm \mathrm{SE}$ ) in blood plasma of cows after dosing with $2 \mathrm{~g}$ of $\mathrm{Sr}$ as $\mathrm{SrCl}_{2}$ in $50 \mathrm{~mL}$ of aqueous solution administered orally $(\square)$ to 8 Friesian cows or via surgically implanted cannulas into the abomasum of 4 lactating Friesian cows $(\diamond)$. 
The quantitative proportion of total absorbed calcium supplied by the rumen has not been determined in cows. However, in sheep, the proportion of total calcium being absorbed before the duodenum, in the small intestine, and in the hindgut was reported to be 50, 35, and 15\%, respectively (Schröder and Breves, 2006). Our findings suggest that calcium absorption from the rumen, like that of magnesium, is a significant component of its supply from food, and this is of particular quantitative importance in providing calcium to meet the demands for milk production at the onset of lactation.

\section{Rumen Calcium Absorption During Lactation}

To study the variability in rumen calcium absorption capacity between cows, we applied the oral strontium absorption test to 21 multiparous, lactating Friesian cows of various ages approximately 3 wk after calving. The mean $( \pm \mathrm{SEM})$ plasma $1,25(\mathrm{OH})_{2} \mathrm{D}$ concentration was $36 \pm 3.7 \mathrm{pg} / \mathrm{mL}$, which was not significantly different from that of 9 mature, nonpregnant, nonlactating heifers $(47 \pm 3.6 \mathrm{pg} / \mathrm{mL})$. The rumen calcium absorption index values and plasma $1,25(\mathrm{OH})_{2} \mathrm{D}$ concentrations were not correlated. However, the mean $( \pm$ SEM) rumen calcium absorption index was $230 \pm 66$ in the 21 lactating cows, whereas that in 6 heifers was significantly lower $(101 \pm 21 ; P<0.05)$. This indicated that rumen calcium absorption capacity is greater in

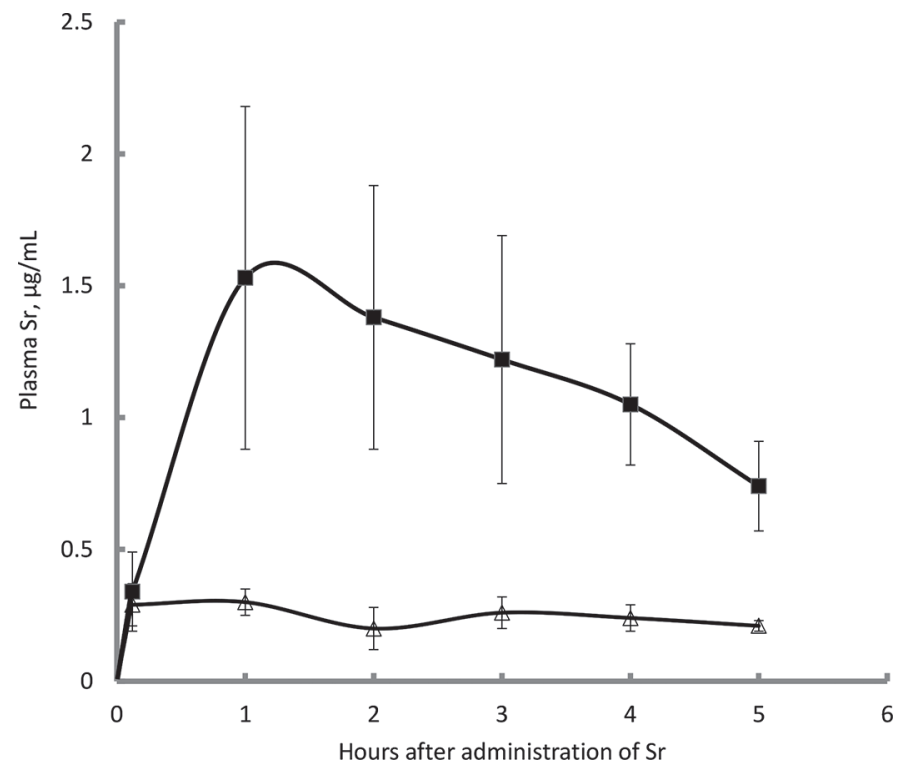

Figure 2. Strontium concentration (mean $\pm \mathrm{SE}$ ) in blood plasma of cows ( $\mathrm{n}=3$ mature Friesian cows) after dosing with $10 \mathrm{~g}$ of strontium as $\mathrm{SrCl}_{2}$ in $50 \mathrm{~mL}$ of solution administered either orally (ם) or by direct injection through the abdominal wall into the lumen of the rumen $(\Delta)$. lactating cows than in mature, but nonlactating, nonpregnant cows.

\section{Rumen Calcium Absorption at the Onset of Lactation}

We studied a group of 14 multiparous Friesian cows from a commercial herd over a period of approximately 3 wk before calving to 3 wk after calving. Four of the cows developed clinical parturient paresis and recovered after standard treatment with a single intravenous infusion of calcium borogluconate. The mean data from the 10 healthy cows and the 4 cows that developed parturient paresis are summarized in Figure 3.

Mean rumen calcium absorption capacities of both groups of cows were similar 3 wk before and 3 wk after calving (Figure 3A). However, at the time of calving, the mean calcium absorption capacity from the rumen of the cows developing parturient paresis was significantly lower than that of the normal cows. Likewise, there were no differences in mean total plasma calcium concentration 3 wk before and 3 wk after calving between the 2 groups, but at the time of calving mean plasma calcium concentration was significantly lower in the parturient paresis group (Figure 3B).

Measurement of the absorption of a standard oral dose of strontium ions, as an indicator of calcium absorption capacity through the rumen epithelium, showed wide variation between cows because of differences in the volume of rumen contents, as expected. Nevertheless, despite this variability, it was evident that rumen calcium absorption capacity had increased at the time of calving compared with precalving values. Once lactation was well established, rumen calcium absorption capacity declined. This suggested that, as in other mammals in established lactation, the loss of calcium in milk was being matched by increased calcium absorption from the small intestine.

The elevated calcium absorption capacity in the rumen at the onset of lactation, as demonstrated by the strontium absorption technique, suggests that this increased capacity is a rapid-response mechanism to maintain calcium homeostasis when large outputs of calcium from blood into milk occur suddenly. This concept is supported by the observation reported here that cows that developed severe hypocalcemia and parturient paresis had significantly lower rumen calcium absorption capacity than cows that did not develop clinical signs of hypocalcemia at the onset of lactation.

The regulatory mechanism for calcium absorption from the rumen has yet to be defined. Calcium transport across the ruminal epithelium has been investigated by the Ussing chamber technique with rumen mucosa from sheep and cows (Wilkens et al., 2011; Schröder et al., 2015). From measurements of the unidirectional flux 

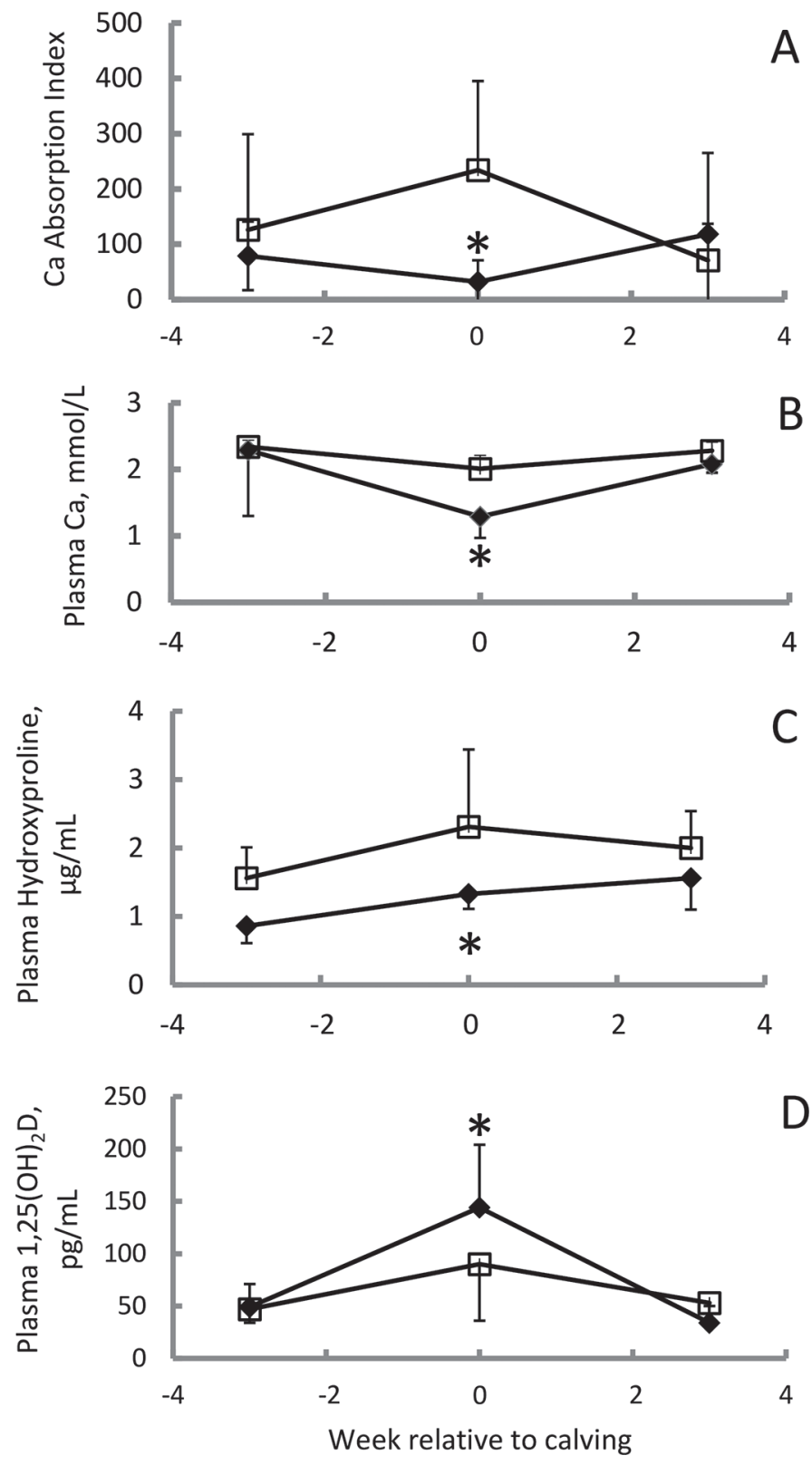

Figure 3. Data (mean $\pm \mathrm{SE}$ ) from 4 Friesian cows $(\checkmark)$ that developed paresis at calving and 10 Friesian cows $(\square)$ that had no paresis at calving. (A) Rumen calcium absorption index (plasma [Sr] at 1.5 $\mathrm{h}$ after dosing $2 \mathrm{~g}$ of $\mathrm{Sr}$ minus initial plasma [Sr], adjusted for a BW of $500 \mathrm{~kg})$; (B) plasma calcium concentration ( $\mathrm{mmol} / \mathrm{L}) ;(\mathrm{C})$ plasma hydroxyproline concentration $(\mu \mathrm{g} / \mathrm{mL})$; and (D) plasma calcitriol $\left[1,25(\mathrm{OH})_{2} \mathrm{D}\right]$ concentration $(\mathrm{pg} / \mathrm{mL})$. ${ }^{*}$ Between-group data points differ significantly $(P<0.05)$.

rates of calcium and mannitol, it was concluded that calcium is mainly absorbed via transcellular mechanisms, whereas the observed minor passage of calcium from the serosal to mucosal compartments is mediated via a paracellular route. Although mRNA for the receptor protein (vitamin D receptor, VDR) for $1,25(\mathrm{OH})_{2} \mathrm{D}$ has been demonstrated in the rumen epithelium in sheep (Wilkens et al., 2016), others have reported that VDR is present at a remarkably low level compared with that in intestinal mucosal cells (Schröder et al., 2001 ), and addition of $1,25(\mathrm{OH})_{2} \mathrm{D}$ to rumen mucosa in Ussing chambers did not change the pattern of calcium transport through those cells (M. R. Wilkens, unpublished results).

Neither transient receptor potential vanilloid channel type 1 (TRPV6) nor calbindin-D9K (CaBPD9K) could be detected in the rumen of sheep, goats, or cows (Wilkens et al., 2011; Schröder et al., 2015). These proteins are expressed in intestinal tissues of many species, and their role in $1,25(\mathrm{OH})_{2} \mathrm{D}$-regulated calcium transport is generally accepted (Hoenderop et al., 2005). Furthermore, feeding a diet restricted in calcium content for several weeks did not change ruminal calcium transport rates in vitro in sheep or in goats. Nevertheless, net absorption of calcium by rumen epithelium, determined in Ussing chambers, was slightly greater in lactating goats than in tissue from nonlactating animals (Klinger et al., 2016; Starke et al., 2016).

We measured plasma concentrations of $1,25(\mathrm{OH})_{2} \mathrm{D}$ at 3 time points. The mean values were similar for both groups at 3 wk before and 3 wk after calving. At the time of calving, mean plasma $1,25(\mathrm{OH})_{2} \mathrm{D}$ levels had increased in both groups but the increase was significantly greater in the group of cows that developed parturient paresis (Figure 3D).

Studies in sheep indicated that infusion of $1 \alpha$-hydroxyvitamin $\mathrm{D}_{3}\left(1 \alpha-\mathrm{OHD}_{3}\right)$ for 10 to $14 \mathrm{~d}$, with subsequent elevated blood concentration of $1,25(\mathrm{OH})_{2} \mathrm{D}$, was associated with a significant increase in rumen calcium absorption capacity (Hyde and Fraser, 2014). Although species differences exist in aspects of ruminant calcium homeostasis (Wilkens et al., 2012), it seems possible that an increase in circulating $1,25(\mathrm{OH})_{2} \mathrm{D}$ is linked to increased calcium absorption capacity in the rumen and small intestine. Why then was rumen calcium absorption capacity decreased in cows that developed parturient paresis when the concentration of $1,25(\mathrm{OH})_{2} \mathrm{D}$ in blood plasma was significantly higher than in cows showing no abnormality? Higher circulating $1,25(\mathrm{OH})_{2} \mathrm{D}$ levels in cows with parturient paresis, compared with those without severe hypocalcemia, have been reported by others (Horst et al., 1978; Horst and Reinhardt, 1983). However, this is not always seen and some cows with marked hypocalcemia may not have elevated blood levels of $1,25(\mathrm{OH})_{2} \mathrm{D}$ (Rodríguez et al., 2016). Also, if $1,25(\mathrm{OH})_{2} \mathrm{D}$ is the hormone promoting increased calcium absorption capacity in the rumen, the mechanism is unlike that for calcium absorption in the small intestine, because there is no TRPV6 and CaBPD9K in the calcium-absorbing epithelial cells in the rumen. From the information presented here and 
from other published studies, it is still not possible to define a regulatory mechanism for calcium absorption by the rumen.

One other feature of cows with parturient paresis is evidence of diminished mobilization of calcium from bone in response to the increased need for calcium to maintain adequate levels in blood at the onset of lactation. The plasma concentration of hydroxyproline, an indicator of bone collagen catabolism, was significantly lower in cows developing parturient paresis than in clinically normal cows (Figure 3C). This and a decrease in serum tartrate-resistant acid phosphatase indicate that mobilization of calcium from bone by the activity of osteoclasts is depressed in cows with parturient paresis (Lappeteläinen et al., 1993; Kurosaki et al., 2007). It has been suggested that although the blood plasma concentration of $1,25(\mathrm{OH})_{2} \mathrm{D}$ and PTH are higher in cows with parturient paresis than in those without clinical signs of hypocalcemia (Horst et al., 1978; Horst and Reinhardt, 1983), bone cell mobilization of calcium in response to PTH may be blunted in cows susceptible to parturient paresis (Goff et al., 2014). Feeding anionic salts prepartum decreases the risk of parturient paresis in dairy cows but the consequent slight systemic acidosis does not, by itself, lead to increased mobilization of calcium from bone (Liesegang et al., 2007). However, the small decrease in $\mathrm{pH}$ in the environment of bone cells may increase the sensitivity of those cells to PTH, which would enhance mobilization of calcium from bone, as suggested by Goff et al. (2014).

A defect in mobilization of calcium from bone at the start of lactation in cows susceptible to parturient paresis would result in a greater decline in serum calcium concentration than in cows with no clinical signs of hypocalcemia at parturition. But the difference in the amount of calcium released from bone between paretic and nonparetic cows is unlikely by itself to explain why blood calcium declines to levels where clinical signs of hypocalcemia develop.

However, the failure to release some calcium from bone in the early stages of lactation could allow blood calcium concentrations to fall to a level where rumen contractility is suppressed (Huber et al., 1981; Daniel, 1983; Ramberg et al., 1984; Jørgensen et al., 1998). In ruminal stasis, absorption of calcium from the rumen would be substantially diminished, as demonstrated with Sr in Figure 2. Even if the rumen capacity for calcium absorption has been increased under the direct or indirect action of $1,25(\mathrm{OH})_{2} \mathrm{D}$ or by other endocrine factors involved in calcium homeostasis, this process becomes ineffective when ruminal stasis occurs (see Figure 2). The treatment of parturient paresis cows by a single intravenous infusion of calcium borogluconate very often abolishes clinical signs and no further treat- ment is required. This suggests that the rumen calcium absorption mechanism is already fully activated in cows with parturient paresis but is unable to operate when rumen contractility ceases. From this, it would appear that the basic defect in calcium homeostasis of many cows developing parturient paresis as milk secretion begins is a failure to mobilize sufficient calcium from bone to prevent a severe decrease in blood calcium concentration. This would lead to ruminal stasis and subsequent low absorption of calcium by the rumen.

\section{CONCLUSIONS}

The concentration of $\mathrm{Sr}$ in blood plasma after absorption from the rumen provides an index of rumen calcium absorption capacity. By applying this technique to cows at the onset of lactation, we can postulate that the basic defect in parturient paresis is a failure to mobilize sufficient calcium from bone to maintain rumen contractility. When the rumen ceases to contract, absorption of calcium by the rumen epithelium is greatly diminished. As calcium absorption by the rumen appears to be a key factor in calcium homeostasis at the onset of lactation, its failure would cause uncontrolled hypocalcemia, leading to parturient paresis. The rapid response of paretic cows to intravenous infusion of calcium ions indicates that activated rumen calcium absorption is fully functional in paretic cows and can operate when rumen contractility is restored.

\section{ACKNOWLEDGMENTS}

The authors thank A. Trube and I. van Ekris (University of Sydney, Sydney, Australia) for their valuable technical laboratory assistance and K. McKean (University of Sydney, Sydney, Australia) for his expert assistance with animal care. This study was supported financially by the former Australian Dairy Research and Development Council (Melbourne, Australia).

\section{REFERENCES}

Beardsworth, L., P. Beardsworth, and A. D. Care. 1989. Calcium fluxes across the wall of the ovine reticulorumen in vivo. Res. Vet. Sci. 47:404-405.

Blum, J. W., C. F. Ramberg, K. G. Johnson Jr., and D. S. Kronfeld. 1972. Calcium (ionized and total), magnesium, phosphorus, and glucose in plasma from parturient cows. Am. J. Vet. Res. 33:51-56.

Dabev, D., and H. Struck. 1971. Microliter determination of free hydroxyproline in blood serum. Biochem. Med. 5:17-21.

Daniel, R. C. 1983. Motility of the rumen and abomasum during hypocalcaemia. Can. J. Comp. Med. 47:276-280.

Ender, F., W. Dishington, and A. Helgebostad. 1971. Calcium balance studies in dairy cows under experimental induction and prevention of hypocalcaemic paresis puerperalis. The solution of the aetiology and the prevention of milk fever by dietary means. Z. Tierphysiol. Tierernahr. Futtermittelkd. 28:2333-2342. 
Goff, J. P., A. Liesegang, and R. L. Horst. 2014. Diet-induced pseudohypoparathyroidism: A hypocalcemia and milk fever risk factor. J. Dairy Sci. 97:1520-1528.

Goings, R. L., N. L. Jacobson, D. C. Beitz, E. T. Littledike, and K. D. Wiggers. 1974. Prevention of parturient paresis by a prepartum, calcium-deficient diet. J. Dairy Sci. 57:1184-1188.

Hodnett, D. W., N. A. Jorgensen, and H. F. DeLuca. 1992. 1-Alphahydroxyvitamin D3 plus 25-hydroxyvitamin D3 reduces parturient paresis in dairy cows fed high dietary calcium. J. Dairy Sci. $75: 485-491$.

Hoenderop, J. G., B. Nilius, and R. J. Bindels. 2005. Calcium absorption across epithelia. Physiol. Rev. 85:373-422.

Höller, H., G. Breves, M. Kocabatmaz, and H. Gerdes. 1988. Flux of calcium across the sheep rumen wall in vivo and in vitro. Q. J. Exp. Physiol. 73:609-618.

Horst, R. L., N. A. Jorgensen, and H. F. DeLuca. 1978. Plasma 1,25-dihydroxyvitamin $\mathrm{D}_{3}$ and parathyroid hormone levels in paretic dairy cows. Am. J. Physiol. 235:E634-E637.

Horst, R. L., and T. A. Reinhardt. 1983. Vitamin D metabolism and its relevance to the periparturient cow. J. Dairy Sci. 66:661-678.

Huber, T. L., R. C. Wilson, A. J. Stattelman, and D. D. Goetsch. 1981. Effect of hypocalcemia on motility of the ruminant stomach. Am. J. Vet. Res. 42:1488-1490.

Hyde, M. L., and D. R. Fraser. 2014. In vivo measurement of the absorption of strontium in the rumen and small intestine of sheep as an index of calcium absorption capacity. Br. J. Nutr. 112:718-724.

Jørgensen, R. J., N. R. Nyengaard, S. Hara, J. M. Enemark, and P. H. Andersen. 1998. Rumen motility during induced hyper- and hypocalcaemia. Acta Vet. Scand. 39:331-338.

Klinger, S., B. Schröder, A. Gemmer, J. Reimers, G. Breves, J. Herrmann, and M. R. Wilkens. 2016. Gastrointestinal transport of calcium and glucose in lactating ewes. Physiol. Rep. 4:e12817. https: //doi.org/10.14814/phy2.12817.

Kurosaki, N., O. Yamato, J. Sato, Y. Naito, F. Mori, S. Imoto, and Y. Maede. 2007. Biomarkers for the activation of calcium metabolism in dairy cows: Elevation of tartrate-resistant acid phosphatase activity by lowering dietary cation-anion difference is associated with the prevention of milk fever. J. Vet. Med. Sci. 69:265-270.

Lappeteläinen, R., E. Lappeteläinen, T. Hassinen, M. Hahl, A. Pirskanen, and P. H. Maenpaa. 1993. Biochemical indicators of bone metabolic activity in bovine periparturient hypocalcemia. Zentralbl. Veterinarmed. A 40:67-72.

Liesegang, A., C. Chiappi, J. Risteli, J. Kessler, and H. D. Hess. 2007. Influence of different calcium contents in diets supplemented with anionic salts on bone metabolism in periparturient dairy cows. J. Anim. Physiol. Anim. Nutr. (Berl.) 91:120-129.

Oetzel, G. R. 2013. Oral calcium supplementation in peripartum dairy cows. Vet. Clin. North Am. Food Anim. Pract. 29:447-455.

Ramberg, C. F. Jr., E. K. Johnson, F. D. Fargo, and D. S. Kronfeld. 1984. Calcium homeostasis in cows, with special reference to parturient hypocalcemia. Am. J. Physiol. 246:R698-R704.
Reinhardt, T. A., and R. L. Hollis. 1986. 1,25-Dihydroxyvitamin D microassay employing radioreceptor techniques. Methods Enzymol. 123:176-185.

Rodríguez, E. M., A. Aris, and A. Bach. 2017. Association between subclinical hypocalcemia and postparturient diseases in dairy cows. J. Dairy Sci. 100:7427-7434.

Rodríguez, E. M., A. Bach, M. Devant, and A. Aris. 2016. Is calcitonin an active hormone in the onset and prevention of hypocalcemia in dairy cattle? J. Dairy Sci. 99:3023-3030.

Schröder, B., and G. Breves. 2006. Mechanisms and regulation of calcium absorption from the gastrointestinal tract in pigs and ruminants: Comparative aspects with special emphasis on hypocalcemia in dairy cows. Anim. Health Res. Rev. 7:31-41.

Schröder, B., W. Goebel, K. Huber, and G. Breves. 2001. No effect of vitamin D3 treatment on active calcium absorption across ruminal epithelium of sheep. J. Vet. Med. A Physiol. Pathol. Clin. Med. 48:353-363.

Schröder, B., M. R. Wilkens, G. E. Ricken, S. Leonhard-Marek, D. R. Fraser, and G. Breves. 2015. Calcium transport in bovine rumen epithelium as affected by luminal Ca concentrations and Ca sources. Physiol. Rep. 3:e12615. https://doi.org/10.14814/phy2.12615.

Seshadri, M. S., T. L. Frankel, D. Lissner, R. S. Mason, and S. Posen. 1985. Bioactive parathyroid hormone in the rat: Effects of calcium and calcitriol. Endocrinology 117:2417-2423.

Sips, A. J., J. C. Netelenbos, R. Barto, P. Lips, and W. J. van der Vijgh. 1994. One-hour test for estimating intestinal absorption of calcium by using stable strontium as a marker. Clin. Chem. 40:257-259.

Starke, S., J. Reimers, A. S. Muscher-Banse, B. Schröder, G. Breves, and M. R. Wilkens. 2016. Gastrointestinal transport of calcium and phosphate in lactating goats. Livest. Sci. 189:23-31.

Steele, R. D. G., and J. H. Torrie. 1981. Principles and Procedures of Statistics: A Biochemical Approach. 2nd ed. McGraw-Hill Book Company, New York, NY.

Wadhwa, D. R., and A. D. Care. 2000. Effects of strontium on the absorption of calcium, magnesium and phosphate ions from the ovine reticulo-rumen. J. Comp. Physiol. B 170:225-229.

Wilkens, M. R., L. M. Maté, N. Schnepel, S. Klinger, A. S. MuscherBanse, M. Ballent, G. Virkel, and A. L. Lifschitz. 2016. Influence of 25-hydroxyvitamin D3 and 1,25-dihydroxyvitamin D3 on expression of P-glycoprotein and cytochrome P450 3A in sheep. J. Steroid Biochem. Mol. Biol. 164:271-276.

Wilkens, M. R., N. Mrochen, G. Breves, and B. Schröder. 2011. Gastrointestinal calcium absorption in sheep is mostly insensitive to an alimentary induced challenge of calcium homeostasis. Comp. Biochem. Physiol. B Biochem. Mol. Biol. 158:199-207.

Wilkens, M. R., J. Richter, D. R. Fraser, A. Liesegang, G. Breves, and B. Schröder. 2012. In contrast to sheep, goats adapt to dietary calcium restriction by increasing intestinal absorption of calcium. Comp. Biochem. Physiol. A Mol. Integr. Physiol. 163:396-406. 